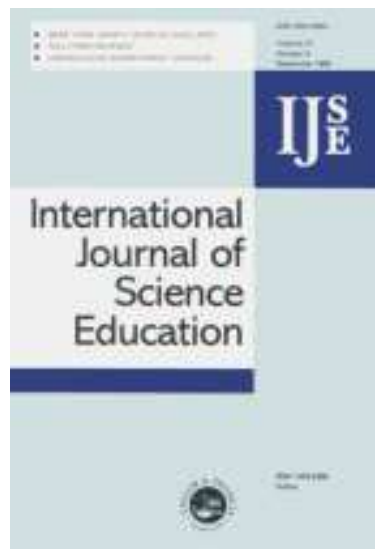

\title{
INTERDISCIPLINARY MATHÉMATICS-PHYSICS APPROACHES TO TEACHING THE CONCEPT OF ANGLE IN ELEMENTARY SCHOOL
}

\begin{tabular}{|r|l|}
\hline Journal: & International Journal of Science Education \\
\hline Manuscript ID: & TSED-2008-0048.R1 \\
\hline Manuscript Type: & Research Paper \\
\hline Keywords: & experimental study, elementary school, science education \\
\hline Keywords (user): & mathematics, angle concept \\
\hline
\end{tabular}

\section{S ScholarONE" \\ Manuscript Central}




\section{INTERDISCIPLINARY MATHEMATICS-PHYSICS APPROACHES TO TEACHING THE CONCEPT OF ANGLE IN ELEMENTARY SCHOOL}

\section{INTRODUCTION}

Over the past twenty years or so, many countries have developed plans to renew science teaching in the schools. The method advocated is the same everywhere: put students in a situation of investigation where they can solve problems like those found in their everyday lives. Whether we are dealing with the hands-on approach in the United States, "la main à la pâte" (hands in the dough) in France, or learning by doing in China, these and other new methods all rely on constructivist theories of learning where a large part of the action is left to the student. For example, the Chicago experiment initiated by Nobel laureate Leon Lederman is described by Sharon McAuliffe in OMNI (Dec 1993): let children work together in small groups rather than passively listen, [...] use simple everyday materials like soap bubbles and beads to illustrate basic principles, $[\ldots]$ move from textbooks and rote memorization to handson, activity-based learning. In short, $[. .$.$] take the drudgery out of math and science and relate$ these subjects to children's lives.

In the area of mathematics teaching, the official 2002 texts for elementary school teaching in France reopened the debate about the relationship between physics, technology, and mathematics. In their general orientation, the texts insist on the merits of articulating the various scientific disciplines. France's National Education Bulletin, for example, states: "As often as possible, the experimental sciences, technology, and mathematics must be related to each other in implementing classroom programs" (Bulletin officiel de l'éducation nationale, No. 1, 14 February 2002, p. 65), and the Mathematics Program Application Documents says: "While mathematics is a tool for acting in daily life, it must also offer useful resources to other disciplines, which, in return, raise questions and trigger progress in mathematics" (Documents d'application des programmes de mathématiques pour cycles 2 et 3, 2002, p. 5).

In the same way in the United States, principles and standards for school mathematics (NCTM, 2000) says that "students should have the opportunity to apply geometric ideas and relationships to other areas of mathematics, to other disciplines, and to problems that arise from their everyday experiences. [...]. For example, students'[...] work on coordinate geometry is related to the maps they create or use in their study of the world. The study of geometry promotes a deeper understanding of many aspects of mathematics, improves students' abstract reasoning and highlights relationships between mathematics and the sciences" (p. 169).

The work presented here falls within this perspective of linking mathematics and science, and is aimed at answering the following question: Can physics-based situations be used to construct geometry concepts? In reference to some general considerations regarding geometry teaching in elementary school, we will begin by presenting our theoretical framework. Next, we will look more specifically at how the concept of angle is acquired by pupils in grades 3,4 and 5. We will present an analysis of this concept, known to be difficult, and then analyse the difficulties pupils have with this concept, while relying on various developmental and didactic studies. These studies, both psychological and epistemic, led us to design teaching-learning sequences in an integrated constructivism perspective (Méheut \& Psillos, 2004). Finally, we 
report three experimental physics-based teaching sequences in which pupils trying to solve a problem are led to experiment in the relevant problem space and model the situation, first in the space of physics and then in the space of geometry. In conclusion, we examine the extent to which each of the problem situations proposed might help pupils overcome the difficulties inherent in the concept of angle, and we discuss their respective merits relative to the objectives set.

\section{THEORETICAL ASSUMPTIONS}

\subsection{Geometry Teaching}

Piaget's Stage Theory of Development

In their work, Piaget and Inhelder (1947(56); 1948(60)) analyzed the construction of representative space in children. They defined three stages of development between the ages of 2 and 11 years. At stage 1, children can only recognize familiar objects, not shapes. At stage 2 (pre-operatory level), they grasp topological (inside-outside, open-close) as well as rectilinear and curvilinear relations, but not metric or Euclidean relations. At the final stage (operatory level), children start to apply metric and Euclidean ones. For Piaget the stages are linked to the child's age and are independent of school learning. However, without questioning the existence of these stages, many recent studies have demonstrated both interand intra-individual variability.

In this developmental approach, the angle plays a special role. According to Piaget and Inhelder (1956): "It is the analysis of the angle which marks the transition from topological relationships to the perception of Euclidean ones. It is not the straight line itself which the child contrasts with round shapes, but rather the conjunction of straight lines which go to form an angle" (p. 30). By the age of 4, the child can consciously distinguish curvilinear shapes from rectilinear ones, but the notion of angle is not constructed until later, as suggested in a study by Piaget, Inhelder, and Szeminska (1960), where children had to copy a figure containing angles (as seen in Figure 1). The children were not able to see this figure as a system of angles until they were 9 years old.

The Van Hiele Theory (1950/1985)

Van Hiele's theory is the one cited the most in studies on geometry teaching. This theory describes five qualitatively different levels in the evolution of geometric thinking (see Crowley, 1987; Burger \& Shaughnessy, 1986).

- At the first level, called "visualization", geometric figures are seen in their entirety and are recognized by their shape. Students can name and identify the most common geometric figures (triangle, square) but without explicitly considering the properties of their components (e.g., the right angles of a square). For Detheux-Jehin and Chenu (2000), children at this level reason by means of "visual prototypes".

- At the second level, called "analysis", students are capable of identifying the components of a figure and can state its necessary properties (e.g., opposite angles in a parallelogram are equal).

- At the third level ("informal deduction/abstraction"), students can logically order the properties of concepts and establish a hierarchy between geometric figures. They can also form and understand abstract definitions of concepts. 
- At the fourth level, called "deduction", they can understand proofs and even produce them.

- At the fifth level, called the "rigor level", students can understand the role of axioms and theorems, study non-Euclidean geometries, and compare different axiomatic systems.

According to this theory, students go through these five levels in succession. However, some other studies discuss this strict hierarchy and reject the idea that each level of thinking is qualitatively different from the others (for a review, see Owens, 1996). As in the Piagetian stages, great variability in performance is observed at any given level, leading to important difficulties in accurately classifying students. In any case, as Wilson and Adams (1992) reported: "Van Hiele's research leads to an important point: students need good activities designed to help them to explore angles and their properties and relationships" (Wilson \& Adams, ibid., p. 7).

The Mitchelmore Theory

Mitchelmore and White describe a process of abstraction that includes three clearly defined steps: familiarity, similarity, and reification. The first level results from "informal" knowledge acquired during early childhood, when connections are made between different situations with surface similarities; this is situated knowledge, i.e., it is situation-specific. At the second level, which is reached by the end of elementary school, children notice deeper similarities between different situations that can be represented by the same geometric figure; they begin to construct different contexts. The last step consists of detecting similarities across contexts, a recognition process that requires a physical or mental action on the part of the learner ("reflective abstraction" as Piaget called it). If the similarity is abstracted to form a concept, it is called an "abstract concept". For these authors, the child recognizes increasingly deep similarities between physical experiences and groups them into specific situations, then general contexts, and finally abstract domains. They stress, however, that these three steps are not mutually "exclusive".

These three theories have a common point: they act as models of how children learn geometry. However Piaget's theory is a theory of development which does not take instruction into account, whereas Van Hiele's and Mitchelmore's theories are dependent upon instruction. For Van Hiele, progressing from one stage to the next depends more on the teaching method adopted than on age, and this makes the geometry-related experiences of the child a determining factor. This author describes the transition from one level to another in five phases, during which_the teacher plays a special role in facilitating this progress, especially in providing guidance about expectations" (Clement \& Battista, 1992): information, guided orientation, explicitation, free orientation, and integration. On their side, Mitchelmore and White (2000) advocate a teaching method called "teaching by abstraction" wherein "students become familiar with several examples of the concept before teaching the concept itself" (familiarity). Then "the concept is taught by finding and making explicit the similarities underlying familiar examples of that concept" (similarity). Lastly, "as students explore the concept in more detail, it becomes increasingly a mental object in its own right." (reification).

The role of geometry teaching in elementary school (grades 1 to 5) has been widely studied, particularly in France by R. Berthelot and M.H. Salin (hereafter abbreviated B\&S). Their theoretical framework is based on the distinction between two separate fields of knowledge: the field of spatial knowledge "needed by the child to control his/her everyday 
relationships to space, and the field of geometry per se". These authors have shown that geometric knowledge and spatial knowledge are closely tied, and that acquiring spatial knowledge is difficult for pupils. At the present time, it is stated in France's official teaching instructions (2002 mathematics curricula) that an understanding of the structure of perceptual space is essential for children: "the principal objective is to enable pupils to improve their 'view of space"'.

However, B\&S (1993-94, 1999-2000) showed that in actual French elementary school (grades 1 to 5) and middle school (grades 6 and 7) classrooms, space and geometry are taught mainly via the ostensive presentation of geometric knowledge: the teacher shows what has to be learned. B\&S concluded from their analyses that the acquisition of spatial knowledge by pupils, although recognized as one of the objectives of geometry teaching, is ill-defined in current teaching programs, and the task of establishing the proper relationships between perceptual space and the concepts taught is left up to the pupil. These authors thus argue for having students do activities in which they model the world of the senses and jointly acquire spatial and geometric knowledge. This approach, like Mitchelmore's and White's, goes against traditional methods where "abstract concepts and procedure are taught before concrete examples and applications (called the ABC method by M\&W). It meets NTCM standards, which also recommend interrelating geometric and spatial knowledge: "Geometric ideas are useful in representing and solving problems in other areas of mathematics and in real-world situations... Spatial reasoning is helpful in using maps, planning routes, designing floor plans, and creating art (p. 41).

\subsection{Our Model}

We chose to use a spatial modelling experiment to make pupils construct a geometric concept that they had never studied in school: the angle. Our goal was to enable children to make the connection between spatial and geometric knowledge by starting from the perceptual world and using it to build the geometric world, in line with the outlook advocated in the new French curricula and NTCM standards. However, difficulty going directly from perceptual space to geometric space, already pointed out by didacticians of mathematics, led us to search for physics situations likely to help pupils acquire geometric concepts. The specificity of this study thus lies in its interdisciplinary framework and its goal: to enable students to build new physics knowledge and new mathematics knowledge in a way that gives them a better grasp than they would have with traditional teaching methods. This approach requires setting up problem situations in which three problem spaces interact: not just the world of perception and the world of geometry, as mathematicians do, but also the world of physics. An analysis and diagram of the objects and problems at play in these three spaces is presented below. The difficulties inherent in each one are different, as are the knowledgebuilding modes. 

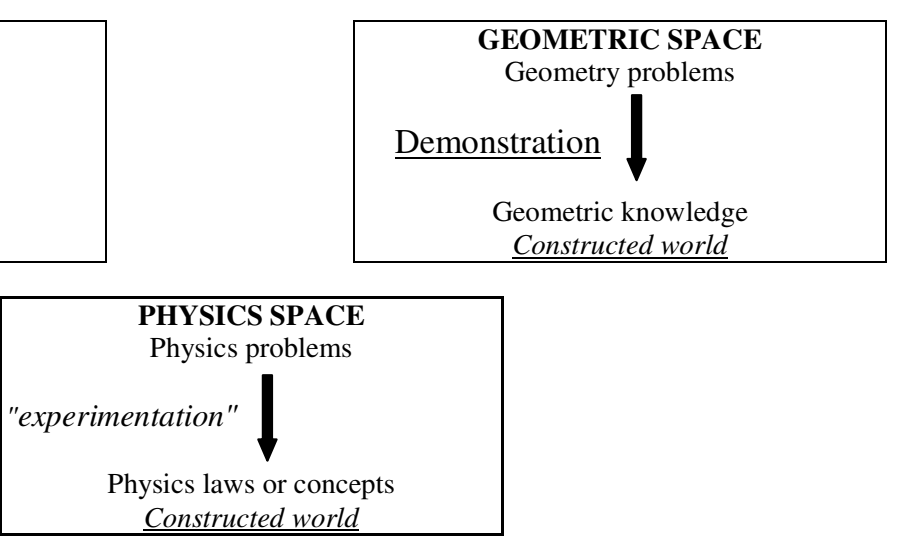

In the space of perception -- that is, the world of real objects perceivable by the senses -- the problems posed are practical ones. In this space, spatial knowledge useful for solving problems is built empirically and validated by comparing the expected result to one actually obtained. In the space of physics, conceptual objects (line of sight, light source, ray), and the problems of physicists are problems that have already been modelled in a theoretical framework, on the basis of a problem in perceptual space. It is therefore a constructed space, and must not be confounded with perceptual or "sensible" space (Chevallard \& Jullien 199091; hereafter abbreviated $C \& J$ ). In this space, knowledge is built in a hypothetico-deductive way (in the broad sense), with experimental validation. The third space, the space of geometry, is a constructed world too, one in which conceptual objects are manipulated (lines, points). The geometer's problems, like those of the physicist, may be ones that model spatial problems, but not necessarily. Although geometry started as a tool for approaching practical problems, in today's scientific community, geometric knowledge is constructed through demonstration.

Elementary school children are too young to be taught geometry by means of formal demonstration, and hence the need to introduce or mobilize geometric concepts in problemsolving activities, in order to show that "geometric ideas are useful in representing and solving problems" (NTCM, 2000, p. 41).

It is hypothesized here that bringing the physics space into the picture could help root the learning process in a spatial reality that is meaningful for pupils, and thereby enable them to create an empirical referent for conceptualizing the targeted concepts. This approach necessitates a dual modelling process: physics modelling of the real world and geometric modelling of the physical world.

Modelling in physics requires starting from a necessarily complex real world and selecting data related to the question being asked. This results in a simplification of reality, which must be reconstructed through thought. The models thus built must be usable for solving the problem for which they were elaborated, i.e., for describing it, explaining it, and predicting certain limited parts of experimental reality. Although this process is complex, the acquisition of modelling skills is an important challenge as early as elementary school.

The table below points out the connections we hope to allow pupils to make between each space, although these two activities should not be seen as strictly consecutive. The dual 
modelling process should lead to the joint acquisition of three types of knowledge: spatial, physical, and geometric.

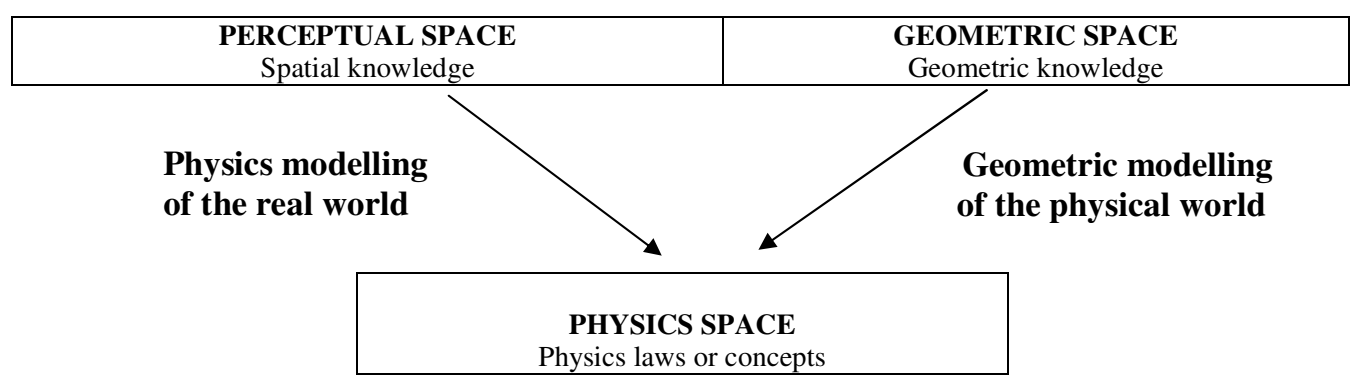

\section{THE CONCEPT OF ANGLE}

\subsection{Different Conceptions of "Angle"}

"Angle" is a highly complex concept, which, according to Mitchelmore and White (hereafter abbreviated M\&W), can be defined in three different ways (M\&W, 1998): as a rotation angle, as a sector angle (the quantity shared by the set of all superimposable angular sectors), and as a pair of half lines that extend from a common point (openness or inclination).

M\&W (1998) studied how children themselves might categorize everyday situations that implicitly involve angles. These authors proposed a classification of these situations based on surface similarities accessible to children rather than on deeper features as in mathematics. They distinguished 7 classes and 14 subclasses:

Table 1: Mitchelmore and White's classification

1. Real or imaginary rotation around a fixed axis (point)

a. unlimited: rotation of the body (doll)

b. limited: door knob or television dial

2. Meeting: an object comprised of two different linear elements

a. incident: pocketknife blade, hands on a clock

b. crossed: pair of scissors

3. Inclination: deviation from the horizontal or vertical

a. line: posts on a mountain side

b. plane: slope of a roof

4. Corner: part of a rigid object forming an angle with two visible sides

a. two planes: that form an angle in space, such as walls and the ground

b. two edges: that form a plane angle, such as the corner of a table or tile

5. Turning: in a series of two or more linear segments

a. objects: turn in the road

b. paths: of the LOGO tortoise, rebound of a ball

6. Direction: deviation of a line from an imaginary fixed line

a. object: needle of a compass

b. path: movement of a ball, a person, a boat

7. Opening: an area of space delineated by two rays originating at the same point 
The three mathematical definitions are found again in these categories. Categories 1 and 5 refer to angles of rotation around a real or imaginary axis, Categories 4 and 7 to sector angles, and Categories 2, 3, and 6 to angles as two lines or half lines, some describing an opening, others an inclination with respect to a fixed direction.

All three facets of the concept can be approached in elementary school. A great deal of work has been done on the angle as a change in course (rotation angle) (e.g. Clément \& Batista 1989), and Vadcard even contended that the largest part of the classroom work on angles has taken place during the use of the LOGO computer environment (Vadcard, 2002). Wilson and Adams (1992) consider that "angle as a rotation, or turn, seems to be especially appropriate for instruction at the elementary school level. This way of thinking about angle allows the student to anchor the concept of angle on the concrete experience of turning her or his own body." They propose activities for learning about angles, first asking students to make full, half, and quarter turns. After these activities, students look for angles in their classroom, form angles with their arms, etc. Mitchelmore (1997), on the contrary, states that this conception must "be regarded as completely inappropriate" for young children because not all the elements of the angle are present in the figure. He considers that a more viable instructional sequence would start by looking for similarities between physical angle contexts that more clearly involve two lines, including crossing, corners, and bent objects.

B\&S experimented with an adidactic introduction of "angle" as a sector angle in the Geometriscrabble setting, where puzzles are put together and the right puzzle piece can be found by looking at the angle to be filled (B\&S, 1994-95). According to Vadcard, the third kind of angle (inclination) "has not been dealt with much in the literature or in the teaching curricula, in spite of its historical importance (it is the angle that Euclid defined) and practical utility (it is used by topographers, for example)." She showed that this conception of the angle could be grasped by tenth graders through the use of an experimental device called "Cabrigeomètre II" (Vadcard, 2002). Other studies have also examined angles as inclinations, in particular, the inclination of the sun's rays (Douek, 1998; Merle \& Munier 2003), or light ray inclination before and after reflection off a mirror (Munier \& Merle, 2007).

\subsection{Pupils' Difficulties Appropriating the Concept of Angle}

Teachers consider the concept of "angle" to be a difficult one, even in grades 6 and 7. In particular, several studies have pointed out an erroneous conception of the angle that resists traditional teaching methods: "The angle is conceived of as the fact of having two segments with a common end and different mediums" (Balacheff, 1988). Here, pupils think that the length of the drawn "sides" affects the size of the angle (B\&S, 1994-95; Wilson \& Adams, 1992; Mitchelmore \& White (1998). This difficulty exists irrespective of the country, and appears to be relatively hard to overcome. A study conducted by Lehrer, Jenkins, and Osana (1998) also showed that "the length of the line segments [used in the angle] had a substantial influence on children's judgments of similarity [...] the effects of length on children's judgments about angles did not diminish during the three years of the study."

B\&S showed that three-fourths of all pupils cannot make sense out of the concept of angle unless it is presented in its primitive, schoolbook form, and that children have trouble recognizing an angle as a subfigure of another figure. Another difficulty inherent in angles is 
the fact that two half lines with the same origin define two angles: a re-entrant angle and a salient angle. This was brought to the fore by Close (1982), who showed that pupils have a very hard time comparing two angles that add up to $360^{\circ}$.

\subsection{Official Teaching Instructions in France}

Angles are studied in grades 3, 4, and 5 in France, but at this age, class work is limited to comparing and drawing angles ("comparison of two angles", "reproduction of a given angle"). Angle measurement is deferred until grade 6. The official 2002 teaching instructions pointed out two major difficulties pupils have in learning this concept: "Pupils must, in particular, become aware of the fact that the lengths of the 'sides' have no effect on the comparison of angles", and they must "compare angles drawn by superimposition or by using a template on particular angles located within a figure (inner angles of a triangle, a quadrilateral ...)". In these current instructions for teachers, it is not stated anywhere what "definition" underlies the vague term "angle". For children, it is clearly out of the question to state a general definition of the term, because as M\&W noted, the "concept of angle [...] is [...] more than the sum of all the different definitions of angle. It is not possible to express this concept in words" (M\&W, 1998). It is surprising, however, that the official curricula offer no guidelines, not even any priorities about which conception pupils should acquire: sector angle, rotation angle, or inclination/openness.

\section{METHOD}

The above analyses regarding both geometry teaching and the concept of angle were the starting point for the design of three teaching sequences aimed at helping pupils "construct" the concept of angle by starting from a situation in the space of perception and transposing it to the space of physics. The first physics situation we set up pertains to the reflection of light off a mirror, the second to the concept of visual field, and the third to the use of a compass. In all three cases, the situations start in a large space (the school playground) and are not limited to the "micro-space" of the sheet of paper. This approach seems particularly well-suited to this concept, for "if geometry were only supposed to serve the technology of micro-space, it could very well do without the notion of angle" (Chevallard \& Julien, 1990-91). It thus seems quite justified to use such space problems, where an understanding of angles is essential.

Through the analysis of these three sequences, we will first test our hypothesis that the introduction of a geometric concept based on a physics situation can lead to better appropriation of the concept. Then we will compare the sequences from various points of view: the chosen conception of the angle, physics and mathematics knowledge, steps taken, etc.

\subsection{Data Collection}

Each teaching sequence developed was tested several times between 2001 and 2004. The teaching sequences were adjusted and refined on the basis of observations made in various classes during the testing period. The detailed presentation that follows in support of our analyses corresponds to the last class of pupils tested on each sequence. The evaluation exercises were also modified in the course of the trial period. The final evaluation results presented below are those obtained for this same "last" class. 
The three experimental classes, in which only one sequence was tested, were fourth-grade classes that had never studied angles except right angles (grades 1 and 2). There were 26 pupils for the mirror sequence, 26 for the compass sequence, and 25 for the visual field sequence. The classes were from different schools, were comparable, and had an average academic standing. The teachers conducted the experimental teaching sequences themselves, which we had prepared in detail and sat in on as observers. Some of the sessions were filmed, while in others the researchers simply took notes. Each sequence included four one-hour sessions, with the fourth session focusing on mathematics. The mathematics session was the same for all three sequences, so it will only be described in detail for the first sequence.

The analysis below deals with both the unfolding of the sessions, the intermediate written traces produced, and individual written tests given after each sequence to evaluate the pupils' work. The tests were designed, conducted, and analyzed by the researchers.

A pre-test/post-test procedure was not possible here because the children had not studied angles before the sequences. Our study therefore falls within a developmental research perspective (Linjse, 1995), and also in a "didactic engineering" framework (Artigue, 1988), which is the approach we used to analyze the teaching sequences. We test our research hypothesis regarding the merits of introducing physical situations, and compare the observed cognitive itineraries with those predicted in the preliminary analysis. However, for this article, we decided to present and compare three didactic situations, so we will report only the most prominent features of these teaching designs.

To better describe the impact of each sequence, the analyses were supplemented with some additional considerations from other research trends. We will compare our pupils' performance, with the results of various studies (B\&S, 1994-95; Close, 1982; Sutherland, 2001). A comparison of our findings with B\&S's seems worthwhile because in both cases, the pupils underwent an adidactic situation, even if the available data does not allow us to draw any conclusions about the comparative impact of the situations (pre-test impossible). On the other hand, by comparing with the other two studies, we will be able to make a direct comparison of our experimental classes with those of pupils who had most likely been taught the notion of angle using a traditional approach.

\subsection{General Preliminary Analysis}

Let us start by outlining our preliminary analysis. We will perform an a priori analysis of the specific features of each teaching sequence before going on to describe what actually took place in the sessions.

The three problem situations devised have a number of common characteristics. Each one starts from a practical problem that the pupils will have to model, as advocated by various authors (B\&S, M\&W) and the NTCM geometry standards: "[children must] use visualization, spatial reasoning, and geometric modeling to solve problems" (p. 41). These problems pertain to a "life size" situation in perceptual space, which pupils worked on in the classroom and out on the school playground, either collectively or in small groups. In each situation, the relevant quantity was the angle, and since taking angles into account to solve the problem was inevitable, it was up to the pupils to discover the relevance of this quantity. The problem situations were specifically designed to bring out the idea of direction in order to invalidate the conception of angle as two segments. This enabled the pupils to become aware of and experimentally verify the fact that angles do not depend on the length of the sides. 
Angle reproduction and/or comparison was induced by the problems themselves and appeared necessary to the pupils. We deliberately did not give the pupils any algorithms that would have been meaningless for them, and they were encouraged to figure out how to reproduce and compare the angles on their own. This approach was based on Piaget, Inhelder, and Szeminska's (1948) work on children's spontaneous geometry. These authors studied the procedures devised by pupils for reproducing Figure 1, which depicts the notion of angle. They concluded that pupils begin to grasp the concept of angle at level IIB (around age 9 or 10 ), when they become able to reproduce this figure by measuring distances $\mathrm{AC}$, and $\mathrm{BC}$ or CK. According to Piaget et al. (1948), "Measuring an angle implies a sui generis coordination of the length of the sides and the width of the opening (two-dimensional measure)." However, we considered here that when pupils use a method based on measures of lengths, they can reproduce a figure, an activity that can be achieved without bringing this concept to bear. For this reason, we decided not to settle for this type of drawing or comparison technique when it occurred, even if the result was correct.

\section{Insert Figure 1 about here}

For pupils in this grade, three devices can be considered: templates, tracing paper, and an instrument with two articulated branches. Each one brings out one of the conceptions of the angle. Templates emphasize the idea of a sector angle. But if templates alone are used, pupils run the risk of grasping only this conception. When angles are reproduced using tracing paper, pupils manipulate pairs of half lines instead of sectors. But this method resembles figure copying, in such a way that when pupils reproduce an angle by tracing it is difficult to know what conceptualization level they have in fact reached. The use of an articulated instrument (a bevel-square made from two narrow strips of poster board attached at one end by a paper fastener, as seen in Figure 2) emphasizes the view of the angle as two half lines (inclination of one direction with respect to another, or space between two directions). When pupils manipulate this instrument, they open and close the branches, which should promote a conception of the angle in terms of openness.

\section{Insert Figure 2 about here}

In order to address as many facets of the angle as possible, we had the pupils use all of these angle comparing and reproducing techniques, in accordance with Mitchelmore's proposals, in order to help the children detect the similarity of different physics situations represented by the same geometric configuration (the angle), before beginning to categorize them (sector, inclination, etc.). It was considered here that even though each class only worked on one physics situation, the use of various techniques would promote awareness of the multiple facets of the concept.

Now let us present a detailed, preliminary analysis and description of each teaching sequence.

\section{TEACHING SEQUENCES}

4.1 Mirror Sequence

4.1.1 Preliminary Analysis 
From the physics standpoint, the aim of this sequence was to lead pupils to discover the law of reflection of light off a mirror. This law includes two parts: (1) all three rays -- the incident ray, the normal relative to the mirror at the point of contact, and the reflected ray -- are in the same plane, and (2) the angle of incidence is equal to the angle of reflection. Given that the pupils' age forces us to limit the sequences to plane geometry, only the second part of the law can be approached at this age. The starting point chosen for "putting the problem in the learner's hands" was a practical problem in three dimensions: the idea is to position a mirror so that the sunlight in the playground will be aimed at a target. Because this situation is too complex for pupils to analyze, we reduced it to a single plane by providing the appropriate tools for manipulating the problem on the flat surface of a table (flat mirrors and lights with one-directional beams), and by imposing several experimental constraints: with the light source sending out a horizontal incident beam of light, the mirror has to be placed vertically on the table. With this setup, we need only determine whether the pupils are able to grasp the equality of the angle of incidence and the angle of reflection.

The use of these devices also allows pupils to visualize the path of light, which is necessary for extracting the law. Indeed, light itself is not "visible"; only the objects it illuminates and that diffuse it (here, the table or a sheet of paper laid on it) show its trajectory. During the manipulations, given the simplicity of the materials used, the light beams are of variable width, slightly divergent, and not very bright. During the diagramming phase, to keep a "record" of their "sense" experiences, pupils can exactly reproduce the trace of light that shows up on the paper. They can also draw lines, and in doing so, they are modelling. This physical modelling process is indispensable for discovering the law, and requires making the transition from the light beam to the light ray, and disregarding the length and brightness of the trace of light.

During diagram analysis, the children will have to consider angles between different types of physical objects (the mirror and light rays), which makes the task more complex. They must "leave" the physics space and "move into" geometric space. If the pupils stay in the physics space, they run the risk of focusing on the traces of light and will therefore see only the angle between the incident and reflected rays, which does not allow them to solve the problem. Indeed, if pupils take only the "turn" of the light into account, they cannot isolate the law of reflection, and if they look solely at the angle of rotation they cannot solve the problem posed. This solving behavior indicates that they have not yet moved from the physics space to the geometric space. Once in the geometric space, the pupils have to identify two equal angles in the figure, which is another known difficulty, as noted above.

This law is well known in its classic form $\alpha=\beta$ (equality of the angle of incidence and the angle of reflection relative to the normal), but it can also be stated in terms of the angles of incidence and reflection relative to the mirror $(\gamma=\delta)$. Both of these approaches are usable with pupils.

\section{Insert Figure 3 about here}

Pupils at this age know about and have been familiarized with axial symmetry for several years, and this knowledge may help them discover the law in that form. However, the law expressed relative to the mirror may in fact be simpler because, unlike the classic form where the normal to the mirror has to be drawn, all of the necessary elements in this formulation are already present in the experimental diagram, a fact which according to Mitchelmore is likely to promote angle recognition in physical situations (Mitchelmore, 1997). In our instructions, 
we did not try to favor one or the other of these two formulations, since both are based on the same conception of the angle, i.e., the angle formed by two half lines, and in particular, the inclination of one direction (that of light) relative to another fixed direction (that of the mirror or the normal).

This problem is indeed quite complex. As Mitchelmore (1997) pointed out, a final obstacle in solving it is that pupils have to ignore the length of the sides, an irrelevant variable. Moreover, Piaget and Inhelder showed that "the equality of the angles of incidence and those of reflection is not discovered until level IIIA (between ages 11-12 and 14)." It may seem ambitious to approach this law in elementary school, but the situation and constraints were set up expressly to facilitate its discovery, and a single pupil was not expected to solve the problem alone. On the contrary, social interactions will be promoted, so the class will end up solving the problem as a group.

The first step was to have the pupils make experimental diagrams and then analyze them; many diagrams had to be compared before their common structure could be grasped.The idea is to analyze the characteristics and properties of two-dimensional geometric shapes and develop mathematical arguments about geometric relationships (NTCM, 2000). If in doing so, they did not discover the law of reflection, a production activity was proposed, namely, draw the reflected ray of a given incident ray. The purpose of this "production" type of activity was to have students compare their hypothetical diagrams to the experimental ones. The comparison of the experimental lines and certain hypothesized but erroneous lines should facilitate the discovery of the invariant in the initial drawings.

\subsubsection{Description and Analysis of the Teaching Sequence}

Session 1: Discovering the Phenomenon (Reflection of Light Off a Mirror) and Qualitative Manipulation

The goal of the first session was to familiarize pupils with the reflection of light off a mirror, in order to "put the problem in their hands". Due to the fact that young pupils may confuse the mirror with a primary source of light, the targeted notion for this session was causality: a mirror cannot reflect light unless it has light shining on it. In addition, at this age, some pupils are still immersed in the idea of "a bath of light" (Guesne, 1984). They think that the "indirect" light in which they are immersed (sunlight that gets diffused by all surrounding objects) can be reflected by a mirror in a given direction, This manipulation would make them see that, to obtain this reflection, the mirror must be hit directly by sunlight.

Outside on the school playground, each pupil was given a mirror and instructed to use it and the light of the sun to "aim at" different objects. Back in the classroom, the teacher put up a simplified map of the playground depicting the sun and a child holding a mirror. Several pupils were asked to draw an $x$ on the map at the place where they thought the spot of light would land on the wall. This phase was supposed to enable the pupils to go from using an empirical procedure on the playground via a trial-and-error approach, to reflecting upon a physics problem.

The pupils proposed a variety of answers and explanations, such as I follow it [the sun], it goes straight ahead and it bounces back, thereby evoking the idea of a light ray for the first time. Certain pupils thought that all of the $x$ 's proposed were correct; others delineated a 
possible area for the spot of light. For the latter, no "precise" law of physics governing the light trajectory seemed to exist, but they apparently already knew intuitively that the position of the light spot was not a question of pure chance.

This phase triggered disagreements among the pupils and led them to the desired physics problem, which was reformulated by the teacher as follows: Can we predict the path of the light after it hits the mirror? The pupils were then given an electrical device they could use to make the path of the light show up as a line on the table (a plastic film container slit at the bottom, with an electrical socket and light bulb inside hooked up to a battery, as seen in Photo $1)$.

By turning the problem into one of predicting the path of the light, pupils can shift from a practical, goal-oriented problem to a physics problem. Of course, the way the question is worded is not trivial. Various studies on older students have shown that when students observe such traces of light, they think they are seeing a light ray, a real, physical object, and this materialization of light is in fact an obstacle to understanding the phenomenon of seeing (Saltiel \& Kaminski, 1996). It is therefore important to avoid creating or reinforcing this wellknown didactic obstacle in physics, the materialized ray, as described by Galili and Hazan (2000): "Rays were conceived literally as material constituents light" and "light staying or travelling in space can be seen from the side".

All pupils noticed that when the mirror and light source changed positions, the light path changed too. They tried several times to find something in this situation that they knew: a right angle or a null angle between the incident ray and the reflected ray. Some explained that the light started up again on the other side, forming an angle. The angle in question was indeed the one between the incident and reflected rays, and the conception brought to bear was that of a rotation angle. But in the present situation, this conception did not enable the children to solve the problem.

\section{Insert Photo 1 about here}

Finally, the teacher called on a pupil to draw the light's path on the map of the playground. The pupil drew the incident ray, and then drew an incorrect reflected ray "at random". Another child pointed to the place where the light "turned" and said: It goes back a little too much, the turn is not as sharp. This shows that he too conceived of the angle as a turn, i.e., as a rotation. Here again, we can see the beginnings of the idea that there exists a physics law which, for particular positions of the light source and mirror, determines the location of the spot of light.

\section{Session 2: Quantitative Manipulation and Diagram Drawing}

For the second session, the aim was to have the children make the transition from perceptual space to physics space, this time by materializing the "path of light" on a piece of paper in order to facilitate the identification of the relevant angles (Mitchelmore, 1997). The teacher asked the pupils to draw several experimental diagrams (as seen in Figure 4). Then each group had to analyze the diagrams and try to answer the question: Can the path of the light be predicted? 
In presenting their results, several groups settled for simply describing the phenomenon. They looked at the diagram and described what they saw: The size of the angle depends on the light. When the light hits the mirror it goes back off and that makes an angle. The angle they talked about was always the angle between the two rays. None of the pupils seemed to consider the angles between the mirror and the rays. As we predicted in our preliminary analysis, a possible interpretation is that the pupils were focusing on angles between two objects of the same physical nature, and therefore didn't "see" angles between objects of different natures. This may reflect the fact that the modelling process was still within the space of physics: at this point for the pupils, the "lines" drawn on the sheet of paper were not yet geometric entities but physical objects. Their attention was thus naturally directed at these objects and their relationship to each other.

Certain pupils brought up the length of the light rays: If the light is not as strong, it's smaller. When the light is closer, it bounces back farther. These comments are related to the device used: the incident light beam could only be seen properly if the light bulb was less than $10 \mathrm{~cm}$ from the mirror, and the reflected rays were only visible for a few centimeters. One of the pupils replied to this remark by explaining that it didn't change anything: As long as the light is in the same place, it doesn't make any difference (he showed how he had moved his light bulb in the direction of the incident ray). Here, the idea of direction was starting to emerge, which validates our initial hypothesis: despite the low-powered lights, the physics problem

| chosen here led to the awareness that the length of the rays was not a relevant quantity here,

The collective phase that followed brought out the idea that "it has to do with angles". Some pupils still thought that no predictions could be made: We send it out [the light], we can't say where it'll go. You can't figure out exactly where it goes. But one pupil insisted: If you know exactly where the mirror and the light bulb are, you should be able to say. The idea of physical determinism was becoming increasingly obvious to the majority of the pupils, but difficulty discovering the law persisted.

\section{Session 3: Discovering the Law of Reflection, and Experimental Verification}

For this session, the pupils started with their experimental drawings from Session 2, which were posted on the board in the state they had been at the end of the preceding session. To help them get past the current barrier, the teacher suggested they try to think of a technique for drawing the reflected ray. Several pupils took a turn coming up to the board and drawing a reflected ray (free hand) on one of the diagrams. One pupil drew a ray that was obviously wrong, moved away from the board and looked at what he had drawn, and then went back to correct it. Only one pupil drew an incorrect ray and left it that way (as seen in Figure 5), which triggered strong reactions from the others. Everyone thought the line was incorrect, but no one knew how to explain why, until one pupil said: The rays have to slant the same amount (which the ray drawn by the pupil obviously did not). The teacher took up this expression and used it to introduce the term "angle", but this time, to talk about the angles between the mirror and the incident and reflected rays. At this point, the classroom atmosphere suggested that the idea was becoming obvious to the pupils: The slant is the same. It's an angle, teacher. It makes angles that are alike. Everyone's attention was directed toward this new idea and all the pupils seemed to be convinced that the "right lines" were the ones where the inclination was the same: "it came back with the same slant", "you can see right away that the slant is different" (on the incorrect diagram). The pupils then looked at all the experimental drawings to validate this hypothesis. It was by comparing the incorrect drawing
Deleted: , and that only the direction of the incident ray relative to the mirror was important

Deleted: immediately 
to the others that the invariant property became apparent to the pupils. This led them to the law of reflection.

\author{
Insert Figure 5 about here
}

Then the teacher prompted the pupils to find tools that could help them draw the reflected ray more accurately, and thus to reproduce angles. They imagined different methods, all based on measures of lengths similar to the triangle reproduction technique mentioned above. The idea of inclination, even if apparently present in certain pupils' minds, was not necessarily explicit for everyone at the end of the third session.

\title{
Session 4: Devising a Technique for Reproducing and Comparing Angles, and Exercises
}

The fourth session was aimed at having the pupils invent and implement different techniques for drawing and comparing angles without measuring lengths. The pupils were given various pieces of colored paper, which they could cut or fold. They quickly devised several techniques for making templates: put the edge of the paper on one of the angle's sides and then fold it to coincide with the other side, or cut the paper so that the second side shows. These "templates" could be used to test the law of reflection on the experimental drawings (compare) and then to draw the reflected rays on other diagrams (reproduce).

Several discussions started up among the pupils to determine whether the ray had to be drawn as long as the side of the template. Without help from the teacher, the pupils arrived at the conclusion that the line could be drawn as long as you want, since it represents a path of light. At this point, they had clearly created an empirical referent that refuted the role of the length of the sides. The mirror setup was then dropped to go on to study angles, and the rest of the activities took place in the geometric world. The physical world now only served as an empirical referent when needed.

Using templates brought the sector-angle conception into the picture, but this technique also may have reinforced the conception of the angle as a "corner" that is part of a surface (the pupils systematically put the corner of the sheet of paper on the angle's vertex). To avoid solidifying this erroneous conception, the remaining work was done on obtuse angles which were not present in this physics situation. The teacher asked a pupil to come to the board to reproduce an obtuse angle. After a few failures despite larger and larger sheets of paper, which shows that some pupils still conceived of the angle as a "corner" that was part of the paper (as seen in Figure 6), this obstacle was surmounted (as seen in Figure 7).

\section{Insert Figure 6 about here Insert Figure 7 about here}

The next step was to get the pupils to imagine and then use other drawing and comparing techniques likely to help them grasp the half-line conception of the angle. Even though this understanding of the concept was the one chosen by the pupils at the onset (the slant is the same on both sides) the template work may have moved this view into the background. First, the pupils proposed using tracing paper and they easily traced the angles. They were no longer manipulating sectors, but pairs of half lines. Yet for some, this method still resembled figure reproduction, as indicated by the fact that they again brought up the problem of the length of the sides, raising the question: Do the traced sides have to be the same length as on the angle to be reproduced? As before, the problem was solved by an exchange among the pupils that 
involved going back to the physics situation. By permitting continuous referral back to the physics space, this problem situation enabled the pupils to go beyond the simple reproduction of a figure.

The pupils commented that these two methods were very slow, and also that templates and tracing paper could not be used again for other angles. With a little prompting from the | teacher, a children proposed using a pair of compasses laid down on the figure. The teacher then introduced the bevel-square quite naturally, as an equivalent but more practical instrument for drawing the sides. Next, the bevel-square was used to introduce some angle terminology and to raise a number of questions, particularly about re-entrant and salient angles (which had not yet been mentioned because they "were not in" the physics situation). The teacher opened the branches of the bevel-square little by little (as seen in Figure 8) and asked how the angle would change (see stage 1 in figure below). The pupils answered in unison that it would be bigger, some using the term more open, others terms like wider or farther apart. The teacher continued to open up the branches until they formed a right angle (stage 2), which was quickly noticed by the pupils: one of them came up to verify with a square that it was in fact a right angle. The teacher continued to spread the branches apart (stage 3), and the pupils commented that the angle was becoming increasingly big or open. When the angle was flat (stage 4), some said: There's no more angle. It looks like a ruler. Others said: When you open it up, there's still an angle, it doesn't disappear. A debate set in, after which the teacher confirmed that the angle still existed and was called a flat angle. When the teacher went on to move the bevel-square branches even farther apart (stage 5), several pupils exclaimed: The angle has gone below. Now it's more closed. Before we were opening and now we're closing. The farther it goes the more closed in gets. One of the pupils said that it could be closed back up from either side, depending on which direction the branches were moved: From one side you open and from the other you close. A new debate began and ended with the idea that for two half lines, there are two angles, a closed angle and an open angle. At this point, the teacher quite naturally introduced the need to label the angles. The subsequent debates took place with very little teacher intervention, and the pupils got highly involved in the discussions. An angle reproduction and comparison exercise followed. It was used to go back over the difficulties (irrelevance of side length, existence of two angles for a pair of half lines).

\subsection{Compass Sequence \\ $\underline{4.2 .1 \text { Preliminary Analysis }}$}

Insert Figure 8 about here

Insert Figure 9 about here

In the compass sequence, an object that could be seen but not reached had to be located by means of a compass and two angle measures (triangulation technique used in topography). This technique is based on the definition of a point as the intersection of two lines: two measures of azimuth (angle between the polar axis and the direction of sight) from two known points determines two half lines that intersect at the place to be located. This idea here was thus to "specify locations and describe spatial relationships using coordinates geometry and over representational systems" (NTCM, 2000). To prevent the use of distances, we had the pupils locate a boat situated on a body of water (as seen in Figure 9). This teaching sequence thus allowed us to introduce angles via the idea of an angle between two directions (north, and 
the direction of the boat's location) and to grasp the concept of angle in real space. It was while drawing a map that the children discovered that the relevant quantity in this situation was an angle between two directions, so the concept of angle emerged as a necessity in this modelling activity. To be able to locate the boat on the map, the pupils had to grasp that the azimuth is the angle between the north and the direction of the boat, unlike most activities using a compass which do not require this understanding.

In the course of our past work, we noted that a majority of children at this age have a very incomplete grasp of the concept of azimuth, even though they have already been taught how to use a compass to move in real space or to find the position of the sun, for example. For most pupils, "azimuth" simply means a number, degrees, or sometimes even a distance, at best a direction without reference to the north. The fact that an azimuth is an angle between a given direction and north has not been acquired at all, which means that these pupils have not built any of the theoretical knowledge underlying the use of a compass.

For this reason, we tried to use empirical knowledge of this instrument, and the actions it permits, to lead our pupils, who had already carried out activities of this type, to grasp the scientific concept of azimuth, and consequently, the concept of angle. An additional feature of this problem situation is that it involves both salient angles and re-entrant angles. The fact that they are oriented angles was not expected to be problematic for pupils at this age, who know how to use a compass technically. The cartography method was validated by comparing the maps made by different groups of pupils.

\subsubsection{Description and Analysis of the Teaching Sequence}

\section{Session 1: Discovering the Need for Triangulation to Locate a Boat on a Lake}

The teacher introduced the problem as a game. The contour of a circular "lake" was drawn outside on the ground of a sports field. The pupils could move around the lake but could stop only at six access points along the bank, where blocks were placed as markers. A ball was positioned "in the middle" of the lake to represent a boat containing a treasure. The task was to find the exact location of the boat because it was going to sink. The pupils were given a map of the lake (as seen in Figure 10) and had to think about what measurements they needed to locate the boat on the map. They all agreed right away that they needed a compass since you can't measure lengths on water. Small groups were set up, each one with a map depicting the access points, and an arrow pointing north that was not parallel to the edge of the paper as it usually is.

\section{Insert Figure 10 about here}

The majority of pupils turned the map to line it up with the visual landmarks (the blocks along the bank), determined the azimuth of the boat from one of the blocks, drew the corresponding line on the map, and then marked the approximate location of the boat on that line based on distance: it's closer to the other edge than to here. A comparison of the maps brought out clear differences, mainly due to poor estimates of the distance to the bank. One pupil discovered that to find out exactly where the boat was, they had to measure the azimuth from two different places, and that the boat would be where the two lines crossed. This idea was taken up and reformulated by several children. Thus, the pupils seemed to understand that they had to measure the azimuths from two different places in order to determine the boat's Deleted: clearly exact location on the map. 
| To be sure the teacher had the children play out the problem: two pupils started out, each from a chosen access point on the bank (block), and walked in the direction indicated by the corresponding azimuth until they ran into each other "at the boat". At the end of this session, the pupils seemed to have grasped the triangulation process, and each group then took two azimuth measures from two different spots on the bank.

\section{Session 2: Group Attempts to Locate the Boat on the Map}

Pairs of pupils were given a map (same map as above) and a photocopy of a compass dial. Their task was to indicate the exact location of the boat (same location as before) using the two azimuths measured in the preceding session. Some pupils had trouble orienting the map using the "compass", and their main difficulty was knowing where and how to correctly tilt the compass to draw the azimuths. Most of the pupils focused on the gradations of the compass and tried to position the corresponding number on the measured azimuth. This means that the necessity of putting the center of the compass on the "boat" was not yet obvious to them. Even among those who positioned the compass correctly, several pupils did not see the need to consider the north and oriented their compass at random, usually with the north-south axis parallel to the edge of the paper.

A collective phase was necessary to bring out the fact that the center of the compass had to be placed on the boat, and that the arrow on the map indicating the north had to be placed parallel to the north arrow on the compass. Once this was clear, the pupils were given pictures of compasses photocopied on tracing paper to help them get past these technical difficulties and locate the boat on the map. This session thus confirmed our earlier observations regarding children's difficulty with the concept of azimuth (little or no attention paid to the polar axis).

Session 3: Individual Drawings, and Emergence of the Concept of Azimuth as an Angle Between Two Directions

Following the discussions of the previous session, each pupil had to locate the boat on the map using the triangulation process. Three-quarters of the pupils managed to perform this task correctly, despite its complexity. However, a class discussion was still needed to define "azimuth". Until then, the pupils had reproduced angles without awareness of the concept itself. The teacher drew a compass on the board (as seen in Figure 11) and asked the pupils to come up and draw a tree in the direction defined by an azimuth of $30^{\circ}$, a house at $90^{\circ}$, a gate at $300^{\circ}$, and a car again at $30^{\circ}$, in order to stress that an azimuth only determines a direction. Several children drew the different objects in the correct places, apparently without difficulty. Then the teacher asked them to explain what an azimuth was. Right from the beginning, the idea of direction prevailed and the children's understanding of the importance of the north was manifest: It starts at the north and goes around. The higher the number, the bigger the turn.

It was when the teacher drew east on the picture of the compass that the concept of angle emerged: North and east, that makes a right angle. There's a right angle. Hey, yeah, they're still angles. These ideas were taken up by other pupils: The wider the angle the more degrees there are. Everyone agreed that the azimuth was the angle between the north and the direction of the boat. The teacher launched a discussion about angles in general. Then he established the vocabulary and conventions for labelling and talking about angles. The concepts of reentrant angle and salient angle were introduced quite naturally, as expected, since these two types of angles "appear" on a compass. 


\section{Session 4: Mathematics Session}

Insert Figure 11 about here

This session unfolded much like the fourth session of the mirror teaching sequence, since certain points had already been addressed at the end of Session 3. In this teaching sequence, once again, the problem of the length of the sides was raised for each reproduction and comparison technique, and the pupils were prompted to discuss this point. To do so, they referred to the real problem situation just experienced (as in the mirror sequence). This repeatedly led them to talk about how the length of the sides had no effect on the size of the angle.

\subsection{Visual Field Sequence \\ 4.3.1 Preliminary Analysis}

This third problem situation is based on the notion of visual field. In the presence of an obstacle, the visual field is delineated by an angle whose vertex is located at the observer and whose sides go through the extremities of the obstacle. Here again, the angle appears in real space between two directions that correspond to two lines of sight.

To grasp the idea that for an observer with a screen in front of him, the space hidden by the screen is delineated by an angle, children must first master the visual behavior used to verify the alignment of points in the gaze direction, which is assumed to be acquired at about the age of 7 (Piaget et al., 1948). The notion of line of sight is based on the concept of rectilinear propagation of light. At this age, the reference model is often one of an indeterminate ray coming from the eye (Guesne, 1984). However, because the direction of propagation does not enter into the problem of interest to us here, we will not attempt to invalidate this erroneous conception of vision._More specifically, they must mobilize the notion of infinite line of sight before they can grasp the concept of visual field. This concept, although not an explicit part of elementary school curricula, is necessary for understanding many astronomical phenomena. For example, one must be able to imagine the visual field of an observer on the Earth in order to conceptualize the diurnal movement of our planet. Yet a number of difficulties with this concept have been noted in studies on astronomy teaching in elementary school (Merle, 1999), where it has been shown that only a third of all children in grades 3, 4, and 5 have a proper understanding of the concept of visual field. The problem situation presented here, designed for teaching the concept of angle, should also help pupils grasp the complex concepts "line of sight" and "visual field", fundamental for understanding certain phenomena in physics. Like the compass situation, this problem brings to bear both salient angles (boundaries of the hidden area) and re-entrant angles (boundaries of the visible area).

\subsubsection{Description and Analysis of the Teaching Sequence}

Session 1: Elaborating the Problem "What Can You See When There's an Obstacle in Front of You?", and Setting Forth Hypotheses

The first session was aimed at helping pupils acquire the concept of visual field. To do this, the teacher handed out a drawing (as seen in Figure 12) depicting several children in danger because they were about to cross the street but could not be seen by a vehicle passing a parked 
bus. The pupils analyzed this situation, but their opinions differed: some thought the children could not be seen by the driver, while others thought they could. A debate set in and ended with the following question, reformulated by the teacher: "What can you see when there's an obstacle in front of you?"

Insert Figure 12 about here

Introducing this question in a road safety situation can help pupils understand the problem. The teacher then proposed exercises where the pupils had to color in the area that the child couldn't see (as seen in Figure 13).

Insert Figure 13 about here

We obtained four types of answers, which are summarized in Table 2 below: $38 \%$ of the children answered correctly, $22 \%$ thought the child could not see the strip perpendicular to the screen ("strip solution"), $18 \%$ drew oblique lines that went through the end points of the screen but did not go through the observer ("non-observer solution"), and $22 \%$ proposed other solutions.

\section{Insert Table 2 about here}

The scores obtained show how difficult it is for pupils to understand the concept of visual field, already noted in the work on astronomy mentioned above (Merle, 1999). We can see here that quite a large percentage of the pupils drew diagonal lines that did not cross the observer. For these pupils, who were aware that what could not be seen was "more than just the strip", the concept "line of sight" had not yet been acquired (which contradicts Piaget's findings) or at the very least, was not operational here. Apparently for them, what is seen is "independent of the observer", as demonstrated in a study on the teaching of geometric optics in high school (Kaminski \& Isambert, 2004).

The various solutions proposed were put up on the board and a debate was organized. The pupils were unable to come to an agreement, so the teacher asked them think about ways to decide which answer was right. The children quickly proposed an experimental verification.

Session 2: Experimenting on the Playground and Determining the Boundaries of the Visible $\underline{\text { Area }}$

This session began with a reminder of the problem to be solved: delineate the areas that can and cannot be seen from a given location in front of an opaque screen. The teacher put a screen and a chair out on the school playground. A pupil-observer sat in the chair, surrounded by a third of the pupils, who took turns sitting down. The rest of the pupils each took a bowling pin and lined up behind the screen where they could not be seen, approximately on the median. For this first step, the teacher asked the pupils to line up close together behind the screen. One by one they moved sideways until coming out into the visible area and stopping when the observer gave the "I can see you" signal. The bowling pin was then put down at that location. Then the whole class came over to observe the locations of the bowling pins, saw that they formed lines on either side of the screen, and verified this by laying out two samecolor ropes along the pins. The pupils also noticed that the lines were "slanted" or "diagonal", which allowed them to rule out the strip hypothesis. 
Next, the teacher asked them if they could have predicted the locations of the bowling pins. One pupil recalled the hypothesis that the boundary lines would pass through the observer. This was verified experimentally by moving the ropes over to the observer. After that, the teacher asked the pupils whether, for the same observer location, they could have stood farther apart in the line behind the screen, and if so, how far back. Some children said that the line could extend beyond the rope, but not everyone was sure. At this point, the observing group was changed and the experiment was repeated with two longer ropes of another color and different lengths. The pupils now used the ropes directly instead of the bowling pins, while leaving the first ropes in place. The observing group was changed again, and the experiment was repeated with a third series of even longer ropes (with the old ropes left in place). Still on the playground, the teacher asked the pupils to comment upon the experiment so that they would arrive together at the conclusion that the boundaries of the visible area were two half lines that went through the screen edges and the observer, and that the lines could be extended as far back as desired.

Back in the classroom, the teacher proposed the following exercise (as seen in Figure 14) to help the pupils build a representation of the maneuvers carried out on the playground: You have a screen in front of you. Color in the area you cannot see. The purpose of the boxes in this exercise was to force the pupils to produce a "qualitative" diagram of the three experiments conducted on the playground without having to introduce the concept of scale.

Insert Figure 14 about here

Session 3: Emergence of the Concept of Angle as a Delineator of the Visible Area, Devising Techniques, and Using Tools to Compare Angles

The teacher put up an enlarged version of the three diagrams as they were at the end of the previous session but without the boxes, and asked: "Is the hidden area the same everywhere, or is it bigger or smaller, and if so, when?" Some pupils thought the hidden area would be the same, but not everyone agreed. For some, the fact that the colored area was bigger or smaller in the different cases meant that the hidden area changed in size, whereas others thought that the boundaries could be extended as far as desired, and thus that the visible area was the same.

Next the teacher gave each pupil the set of three diagrams with sides of different lengths, and asked them to think up a technique for finding out if the area was the same. In other words, he had the pupils devise techniques for comparing angles without actually employing the term "angle". Some pupils did this by superimposing the three diagrams against a window pane and looking through the paper. The teacher handed out tracing paper to all pupils, who easily verified that the hidden areas were in fact superimposed. This led them to the conclusion that the hidden area was the same for a given observer position, no matter how long the ropes were.

Then the teacher asked the following question: What determines the edges of the hidden area? Some pupils quickly spoke of "triangles" (or V's) but the teacher pointed out that there was no third side, and after a few minutes of discussion, the term "angle" came up. A conclusion was jointly drawn: the hidden area was delineated by an angle, and this angle was the same in all three diagrams, even though the sides had different lengths.

After this comparison task, the teacher gave an angle copying exercise and asked the pupils to devise other techniques for comparing and reproducing angles. Despite a few manipulation 
difficulties, the pupils managed to produce templates using various techniques, mostly folding. The teacher then proposed bevel-squares and asked the pupils to reproduce the same angle again with this instrument, which they had no trouble doing.

\section{Session 4: Mathematics Session}

While going over the material, the teacher took the opportunity to introduce some vocabulary words: "We have seen that the edges of the hidden area were determined by an angle whose vertex was the observer and whose sides went through the ends of the screen." Then, as in the mirror sequence, the teacher used a bevel-square to trigger discussions. When the problem of the existence of two different angles for the same pair of half lines was brought up, he went back to the initial problem situation: "The 'closed' one is the area that cannot be seen (except for the small triangle in front) and the 'open' one is the part that can be seen."

\section{OVERALL ANALYSIS OF THE TEACHING SEQUENCES}

\subsection{Points in Common}

For all three teaching sequences, we can see that the concept-emergence phase was long. As requested, the teachers did not rush and let the pupils discover that the key to the problem was "the angle". During the preparation stages, we had predicted that only two sessions would suffice for the concept to emerge, but in each case we had to "patiently" wait one more session. Indeed, for all three problem situations, the pupils became aware of the concept in the course of the third session, and always in a sudden way: The slant is the same. It's an angle, teacher. And the others always agreed unanimously with the pupil's proposal: Yes, that's its. They're angles! So, two sessions were not sufficient to convey the idea of angle, but the students apparently grasped the idea in the third session. This abrupt and collective phenomenon, where the students as a group suddenly hit upon a correct understanding of angle, is worth examining more deeply in future research, but it already has pedagogical implications. Teachers are sometimes inclined not to wait and to move ahead with teaching plans. Yet, the amount of time taken here for the concept of angle to emerge from the physics problem seems to be necessary for the proper appropriation of this concept by pupils.

In each of the teaching sequences, the reproduction and/or comparison techniques were automatically induced by the problem situation and therefore did not have to be introduced by the teacher. The first technique the pupils imagined often involved the measurement of lengths, in which case the teacher had to prompt the pupils to think of other methods (such as tracing paper or templates). As we have seen, the fact of having to use these alternative reproduction techniques avoided mere figure copying by the pupils. The bevel-square triggered numerous discussions among the children about points that caused problems for them (flat angles, re-entrant and salient angles), so the use of this instrument seems to be an essential feature of the approach.

From a mathematical point of view, the physics situations proposed enabled the pupils to invalidate the idea that the length of the sides plays a role, which was one of the main reasons why we introduced this concept using problems where the idea of "direction" stood out. The problem of the sides' lengths was always brought up by the pupils, no matter what technique was used. This obstacle was overcome in each case by going back to the physics situation. In this way, the pupils' first contact with the concept of angle did not take place in a primitive,
Deleted: It seems that the amount of time it took here for the concept of angle to emerge from the physics problem is necessary for the proper appropriation of this concept by pupils.

Deleted: II 
schoolbook type of situation. This has two advantages: not only does it avoid a didactic obstacle, but it also supplies the pupils with an empirical referent that enables them to discard the misconception that lengths are important. These situations make the concept of angle meaningful and break away from conventional teaching contexts that are far-removed from a child's experience with physics. "Angle" can then be approached as a geometric object.

\subsection{Differences}

Although the three problem situations have a number of shared characteristics, they differ in several respects, which will be analyzed below and then summarized in the table 3 .

The conception of the angle naturally brought out by the problem situations is not the same in each case. In the mirror problem, it was the rotation angle that prevailed for certain pupils, but this conception did not help them solve the problem. When they extracted the law of reflection, it was an inclination with respect to a given direction (here, that of the mirror) that was mobilized. For the compass problem, it was also an inclination of a direction relative to another (the north) that the pupils used to solve the problem. In the visual field problem, it was mainly the idea of a sector angle. The reason for having the pupils try out three reproduction techniques was to prevent them from confining themselves to a single conception of the angle. During these activities, they always activated two conceptions of the angle: sector angle with templates, and opening or widening with the bevel-square. The latter instrument also allowed us to introduce obtuse and re-entrant angles in situations where they do not occur naturally. The mirror problem was the only one that led the pupils to notice two equal angles in a figure, a difficulty already noted in research on mathematics teaching. On the other hand, this problem situation did not involve salient angles, unlike the other two which also included re-entrant angles (in a natural way for the compass, and as the boundaries of the visible space for visual fields).

In each teaching sequence, the pupils managed to correctly accomplish the required task and thus to identify the quantity "angle" as the relevant entity for the problem at hand: they identified two equal angles in a figure in order to draw the ray reflected by a mirror, they took the north into account to locate a boat on a map, and they identified the invariant in three diagrams depicting a visual field. From the standpoint of physics knowledge and skill acquisition, these problem situations offer a number of advantages. In addition to providing practice with the modelling of perceptual space, two of the sequences set the stage for leading pupils to apply the experimental method, i.e., to set forth hypotheses and test them experimentally.

Table 3: comparison of the three sequences 


\begin{tabular}{|c|c|c|c|}
\hline & Mirror & Compass & Visual Field \\
\hline $\begin{array}{c}\text { Prevailing conception of } \\
\text { "angle" }\end{array}$ & $\begin{array}{c}\text { Inclination of a direction } \\
\text { relative to the direction of a } \\
\text { mirror }\end{array}$ & $\begin{array}{c}\text { Inclination of a direction } \\
\text { relative to a fixed direction } \\
(\mathrm{N})\end{array}$ & Angular sector \\
\hline Angle in a figure & Yes & No & No \\
\hline $\begin{array}{l}\text { Re-entrant and salient } \\
\text { angles }\end{array}$ & No & Yes & Yes \\
\hline $\begin{array}{l}\text { Realizing that "angle" is the } \\
\text { relevant quantity }\end{array}$ & $\begin{array}{l}\text { As an invariant in a figure } \\
\text { for making predictions }\end{array}$ & $\begin{array}{c}\text { As necessary for } \\
\text { diagramming a situation on } \\
\text { a map }\end{array}$ & $\begin{array}{c}\text { As an invariant of several } \\
\text { diagrams }\end{array}$ \\
\hline $\begin{array}{l}\text { Activity leading to the } \\
\text { realization }\end{array}$ & $\begin{array}{c}\text { Analysis and production of } \\
\text { a diagram }\end{array}$ & Production of a map & Analysis of several diagrams \\
\hline $\begin{array}{l}\text { Activity induced by the } \\
\text { problem situation }\end{array}$ & $\begin{array}{l}\text { Comparison and } \\
\text { reproduction }\end{array}$ & Reproduction & Comparison \\
\hline Physics knowledge acquired & $\begin{array}{l}\text { Law of physics: } \\
\text { reflection of light off a } \\
\text { mirror } \\
\end{array}$ & $\begin{array}{c}\text { Physics concepts: Line of } \\
\text { sight } \\
\text { Azimuth } \\
\end{array}$ & $\begin{array}{l}\text { Physics concepts: Line of sight } \\
\text { Visual field }\end{array}$ \\
\hline $\begin{array}{l}\text { Methods implemented by } \\
\text { pupils }\end{array}$ & $\begin{array}{c}\text { Modelling } \\
\text { Experimental method }\end{array}$ & Modelling & $\begin{array}{c}\text { Modelling } \\
\text { Experimental method }\end{array}$ \\
\hline
\end{tabular}

\section{EVALUATION}

The evaluation phase had three objectives. The first was to assess how well the pupils had assimilated the concept of angle and if they were capable of reapplying their knowledge to different geometry problems, and more specifically, whether they had overcome the lengthof-sides obstacle and could recognize angles in a closed figure (which had not been done in class). The second was to find out if the pupils could correctly solve the physics problems studied. The third was to determine whether they could reapply their knowledge to a physics problem other than the one studied.

For the evaluations, the pupils were given a graduated ruler, colored paper for making templates, tracing paper, and a bevel-square. They were free to use whatever instruments and techniques they desired.

\subsection{Mathematics Test}

The first three exercises were "standard" mathematics problems selected or devised for the purposes of comparing our pupils' results with those of B\&S (1994-95) and Close (1982). The first problem is taken from the $B \& S$ article (as seen in figure 15). Equal-size angles had to be identified in a closed figure (a triangle). None of the answers could be given by mere observation because the angles looked equal. The equal angles had different-length sides, whereas the nearly-equal angles had same-length sides.

\section{Insert Figure 15 about here}

The material for the second exercise (as seen in Figure 16) was taken from the same article and supplemented with two obtuse angles from Close (angles $\mathrm{G}$ and $\mathrm{H}$ ). The pupils had to compare eight pairs of angles designed to verify whether they had overcome the obstacles mentioned above. Out of the eight comparisons, six tested their understanding that angle size is independent of the sides' lengths and their grasp of the relationship "bigger than" between two angles of the same type. The other two questions involved comparing a salient angle and a re-entrant angle whose sum was $360^{\circ}$; in one, the salient angle was acute and in the other it was obtuse. The third exercise was an angle reproduction exercise. 
We compared our results with those obtained by sixth graders in France at the end of the school year, although the methods used were different: our pupils were not required to employ any particular method, whereas the sixth graders probably had to use a protractor. Our pupils' scores for the first exercise were lower than those obtained by B\&S, especially for angles that were nearly the same size. The tables below give the percent of correct answers (with the number of pupils tested in parentheses).

\begin{tabular}{|l|l|l|l|l|}
\hline & B\&S (41) & Mirror (26) & Compass (26) & Visual Field (25) \\
\hline Exercise 1 & $85 \%$ & $81 \%$ & $84 \%$ & $76 \%$ \\
\hline
\end{tabular}

Table 4

Our pupils' procedures were not very precise: they often used tracing paper or a template whose sides were too short, or they did not hold down the branches of the bevel-square firmly enough, leaving too much play and thereby preventing accurate comparisons. In future teaching sequences, then, more emphasis should be placed on precision throughout the sessions, and on the last session, the pupils should be assigned exercises where inaccuracy leads to failure.

The results for the second exercise involving the comparison of angles of the same type were as follows:

\begin{tabular}{|c|c|c|c|c|}
\hline & B\&S (41) & Mirror (26) & Compass (26) & Visual Field (25) \\
\hline Angles of same type & $74 \%$ to $93 \%$ & $77 \%$ to $96 \%$ & $60 \%$ to $92 \%$ & $60 \%$ to $92 \%$ \\
\hline
\end{tabular}

Table 5

The best scores were similar across problem situations, but the worst ones were much lower in the compass and visual field groups. The worst scores of all were obtained for two angles of very similar size, probably due to the accuracy problems mentioned above.

In general, questions that require comparing a salient angle and a re-entrant angle that add up to $360^{\circ}$ cause the greatest number of problems.

\begin{tabular}{|l|c|c|}
\cline { 2 - 3 } \multicolumn{1}{c|}{} & $\mathrm{E}>\mathrm{C}$ & $\mathrm{G}>\mathrm{H}$ \\
\hline B\&S (41) & $27 \%$ & $/$ \\
\hline Close (21) & $52 \%$ & $14 \%$ \\
\hline Mirror (26) & $69 \%$ & $77 \%$ \\
\hline Compass (26) & $48 \%$ & $52 \%$ \\
\hline Visual Field (25) & $40 \%$ & $52 \%$ \\
\hline \multicolumn{2}{|c|}{ Table 6 }
\end{tabular}

These questions were difficult, but our pupils obtained much better scores as a whole than the $B \& S$ and Close pupils did. This suggests that the sessions proposed here were effective for teaching salient and re-entrant angles, even if not for all pupils. Our results can be assumed to result from the numerous debates raised during the use of the bevel-square.

The most frequent mistakes concerned determining the equality of two angles whose sum was $360^{\circ}$. There does seem to be a general conceptual difficulty here, as demonstrated by Close. 
The percentage of pupils capable of reproducing an angle by the end of sixth grade is $70 \%$. In three of our classes, $96 \%, 88 \%$, and $84 \%$ of the angles reproduced were perfect, which means that our pupils did quite a bit better even though they were one or two years younger. This raises the question of the effectiveness of requiring pupils to use a protractor. This instrument is obviously necessary for measuring angles, but it may not be the best technique for reproducing them. Given that pupils clearly have trouble using a protractor, it seems unwise to totally abandon the template, which only requires scratch paper as supplies.

\subsection{Situation-Specific Tests}

For each teaching sequence, an example of a situation-specific exercise is given below.

\section{$\underline{\text { Mirror Exercise }}$}

\section{Insert Figure 17 about here}

In this exercise (as seen in Figure 17), the pupils had to determine which of three bowling pins would be lit up by a reflected ray. The correct answer was pin number 1 . For this pin, the length of the incident ray was different from the "length" of the reflected ray (up to the pin of course), whereas these lengths were equal for pin number 2 . The mirror was purposely drawn in a "random" position (neither perpendicular nor parallel to the edge of the paper). The percentage of correct answers was 73\%. Only two pupils out of 26 selected the bowling pin for which the length of the incident ray was equal to the "length" of the reflected ray, although we cannot be sure that this was why they failed. Indeed, to make sure the pupils could not choose the right answer "at a glance", the bowling pins were placed very close together. These incorrect answers may therefore have been due to an accuracy problem.

\section{Compass Exercise}

\section{Insert Figure 18 about here}

This exercise (as seen in Figure 18) was aimed at assessing the pupils' understanding of the triangulation method. The approach was the opposite to that used in class: the pupils had a map showing the position of a treasure and had to explain how to find it to two other children. In fact, the children had to proceed in two steps: materialize the angle that "described" the problem, and then measure it. Correct explanations were given $88 \%$ of the time. This score is extremely high, given the difficulty of this task. The triangulation process is very complex, particularly for young children, but only two pupils "failed", one of whom gave two very approximate azimuths and did not answer the question. From these results, we can conclude that the majority of the children had grasped the concept of azimuth.

\section{$\underline{\text { Visual Field Exercise }}$}

In this exercise, the pupils were told that a child was seated facing a screen, but they were not given a diagram. They had to state whether the hidden area would get bigger, smaller or the same when the child moved toward the screen, when the child moved away from the screen, or when the screen was made wider (this question was a short answer test). They were allowed to draw diagrams to find the answers. Eighty percent of the children answered the first two questions correctly, 76\% answered the third question correctly, and $72 \%$ got all three questions right. Thus, after the visual field teaching sequence, nearly three-fourths of the 
pupils were capable of mastering the functional relationship between the size of the angle defining a visual field, and the observer's location on the median or the width of the screen.

\subsection{Transfer Test}

For each teaching sequence, the pupils were given a description of a problem situation they had not studied in class and in which "angle" was the relevant quantity. Let us illustrate here with the transfer problem proposed after the visual field sequence. The pupils were told about an experiment conducted by some children who wanted to determine the location of the sun in the sky. They were given two drawings each showing a post with its shadow behind it. The two drawings depicted the same time of day but the posts were of different heights. First, the pupils were asked what was the same and what was different in the two drawings. Then they had to fill in an incomplete diagram showing only the ground and the post, at the same time of day but with a taller post (as seen in Figure 19).

\section{Insert Figure 19 about here}

To get this exercise right, the children had to first notice that the angles in the two figures were equal. Then on the drawing, they had to reproduce the angle with very long sides, put one side of the angle on the ground, and slide it until the other side touched the top of the post. Out of 25 pupils, seven performed the exercise correctly, i.e., they noticed the equality of the angles between the ray of sun and the ground, and they drew the right line; two pupils noticed the equality of the angles but made mistakes in drawing the angle; eight others didn't say that the angles were equal but drew correct lines. Thus, a relatively high percentage of the pupils were able to perform this complex task.

Moreover, this situation was actually implemented in several other classes. The pupils had trouble detecting the equality of the angles in the first diagrams, even though they had conducted and then diagrammed the experiment themselves (Merle \& Munier, 2003).

\section{CONCLUSION AND PERSPECTIVES}

The evaluations showed that at the end of each teaching sequence, the pupils had a certain grasp of the concept of angle, and the misconception of the angle as two segments with the same origin had been discarded by a large majority of the pupils. From the mathematics standpoint, then, we can conclude that our teaching sequences were effective for reaching the goals we set. Situation-specific exercises were used here to determine whether the pupils had acquired the physics and geometry knowledge needed to solve the problems they had studied. Given the difficulty of the tasks, the results indicate that a large number of pupils had truly appropriated the physics knowledge at play. The transfer exercises gave rise to poorer scores. Certain pupils were nevertheless able to ascertain that the angle was the relevant quantity in complex problems they had never come across before. It thus seems that using spatial problems in which the angle plays a highly meaningful role can enable many pupils to successfully grasp new physics situations. These results prove the effectiveness of these teaching-learning sequences. We can therefore consider that we have produced "good didactical structures". 
Our research hypotheses were validated also by the results reported here, both in terms of the evaluations and in the way the teaching sequences unfolded: using a physics framework to introduce angles in problem situations taken from perceptual space is feasible in the elementary school classroom. The introduction of physics situations that bring the idea of direction into the picture can enable pupils to discard the idea that the length of the sides plays a role in determining what angle is at stake. The teaching sequences presented in this article permitted pupils to learn a geometry concept, the angle, which they "constructed" from physical reality. It was indeed "geometry as a model of space" that constituted the framework of our study (Gobert, 2001): a problem situation involving spatial experimentation enabled pupils to acquire geometric knowledge, the notion of angle, which in turn allowed them to discover a physics law or concept.

The students were indeed led to articulate the sensible, physical, and geometric worlds by working on a sheet of paper that acted as a medium and an intermediary between these worlds. For example, it was by schematically representing light beams as rays that the students were able to move from the sensible space to the physics space, before situating themselves in the geometric space where they discovered the equality of the angles and accessed the concept of angle and the law of light reflection. Similarly for the compass sequence: it was indeed when the pupils had to draw the map that they became aware of the importance of the north and could "construct" the notion of azimuth. In the course of this work, they made connections between spatial, physical, and geometric knowledge.

Thus, by interrelating different spaces, the pupils were able to acquire knowledge in the domains of mathematics and physics. They also developed modelling skills, which is another one of the teaching goals for elementary school. This is a strong point of the present work, for despite the recognized importance of modelling, classroom constraints are such that few studies have proposed teaching sequences where students work in a space larger than a classroom or a sheet of paper.

Concerning the respective advantages of each of the problem situations we devised, we have seen that different conceptions of the angle were emphasized in each. When the pupils used a bevel-square and templates, they mobilized at least two different conceptions: angles as two half lines (openness, inclination) and angles as sectors. In order to solidify the acquisition of this concept, it would be useful in the future to have each class work on two sequences rather than just one as we did here, in line with M\&W's suggestion. These authors believe that for pupils to fully conceptualize the concept of angle, they must be able to recognize its different facets (inclination, rotation, sector) in all situations they come across in daily life, and to make connections between the different contexts where angles are found (M\&W, 1998). A second teaching sequence using the same dual-modelling approach to another physics problem should help pupils expand and strengthen those connections.

We have shown that the visual field sequence, which brings out the sector conception of the angle, is beneficial right from grade 3 . The other two sequences, mirror and compass, appear to be more complex, which suggests that they might be more suitable for situations where the teacher returns to a topic in order to further develop already acquired notions and techniques, here the angular-sector conception and angle comparison. After the visual field sequence in grade 3, the teacher could pursue the study of angles in grades 4 and 5 using one or both of the other sequences. One can imagine a progression over two or three years where pupils first construct and then "reinvest" in the notion of angle by means of various modelling activities. 
Teaching the concept of angle in elementary school 29

References

Artigue, M. (1988). Ingénierie didactique. Recherches en didactique des Mathématiques, 9(3), 281-308.

Balacheff, N. (1988). Study of the process of proving in mathematics among middle school students. Unpublished Thesis, Université de Grenoble 1, 395-464.

Berthelot, R., \& Salin, M. H. (1993-94). L'enseignement de la géométrie à l'école primaire, Grand N, 53, 39-56.

Berthelot, R., \& Salin, M. H. (1994-95). Un processus d'enseignement des angles au cycle III, Grand N, 56, 69-116.

Berthelot, R., \& Salin, M. H. (1999-2000). L'enseignement de l'espace à l'école primaire, Grand N, 65, 37-59.

Berthelot, R., \& Salin, M. H. (1992). L'enseignement de l'espace et de la géométrie dans la scolarité obligatoire. Unpublished Thesis, Université de Bordeaux 1.

Berthelot, R., \& Salin, M. H. (1998). The Role of Pupil's Spatial Knowledge in the Elementary Teaching of Geometry. In C. Mammana and V. Villani (Eds.) Perspectives on the Teaching of Geometry for the $21^{\text {st }}$ Century (pp. 71-82). Dordrecht, Kluwer Academic Publishers.

Chevallard, Y., \& Jullien, M. (1990-1991). Autour de l'enseignement de la géométrie au collège, Petit $x, 27,41-76$.

Clements, D. H., \& Battista, M. T. (1992). geometry and spatial reasoning. In D. A. Grouwes (Eds.) Handbook of research on mathematics teaching and learning (pp.420-464). New York, Macmillan publishing Co.

Close, G. S. (1982). Children's understandind of angle at primary/secondary transfert age. Master of science, Polytechnic of the South Bank, London.

Douek, N. (1998). Analysis of a long term construction of the angle concept in the field of experience of sunshadows, Proceedings psychology mathematics education of PMEXXII, 2, pp. 264-271.

Galili, I., \& Hazan, A. (2000). Learners' knowledge in optics: Interpretation, structure and analysis. International Journal of Science Education, 22(1), 57-88.

Gobert, S. (2001). Didactic questions linked to reports between geometry and sensible space, for elementary school teaching. Unpublished thesis, Université de Paris 7.

Guesne, E. (1984). Children's ideas about light. In E.J. Wenham (Eds.) New Trends in Physics Teaching (pp. 179-192). Paris, UNESCO.

Kaminski, W., \& Isambert, J. (2004). The plane mirror in eleventh grade math: Reverse image or reflected light?. Bulletin de l'Union des Physiciens, 866, 1069-1080.

Lehrer, R., Jenkins, M., \& Osana, H. (1998). Longitudinal study of children's reasoning about space and geometry. In R. Lehrer \& D. Chazan (Eds.) Designing learning environments for developing understanding of geometry and space (pp. 137-167). Mahwah, NJ: Erlbaum.

Linjse, P. L. (1995). 'Developmental Research' as a way to an empirically based 'Didactical Structure' of science. Science Education, 79(2), 189-199.

Meheut, M., \& Psillos, D. (2004). Teaching-learning sequences: aims and tools for science education research. International Journal of Science Education, 26(5), 515-535.

Merle, H. (1999). Difficulties in conceptualizing earth's rotation around itself. Didaskalia, 10, 61-94.

Merle, H., \& Munier, V. (2003). How to conceptualize the height of the sun as angle in grades 3 to 5?. Aster, 36, 39-68.

Mitchelmore, M. (1997). Children's informal knowledge of physical angle situations. Learning and instruction. 7(1), 1-19. 
Mitchelmore, M. (1998). Young students' concept on turning and angle. Cognition and Instruction, 16(3), 265-284.

Mitchelmore, M., \& White, P. (1998). Development of angle concepts: A framework for research. Mathematics education research journal, 10(3), 4-27.

Mitchelmore, M., \& White, P. (2000). Teaching for abstraction reconstructing constructivism, in J. Bana \& A. Chapman (Eds.) Proceedings of the $23^{\text {rd }}$ annual conference of the mathematics education research association of Australasia (pp. 432-439). Freemantle.

Munier, V., \& Merle, H. (2007). Une approche interdisciplinaire mathématiques-physique du concept d'angle à l'école élémentaire. Recherches en didactique des Mathématiques, 27(3), 349-388.

Piaget, J. and Inhelder, B. (1955). From child logic to adolescent logic. Paris, Presses Universitaires de France.

Piaget, J., Inhelder, B. and Szeminska, A. (1960). The child's conception of geometry. New York, Basic Books, Inc.

Vadcard, L. (2002). Conceptions of the angle among tenth grade students. Recherches en didactique des Mathématiques, 22 (1), 77-119.

Wilson, P. S. and Adams, V. M. (1992). A dynamic way to teach angle and angle measure. Arithmetic Teacher, 39 5, 6-13. 


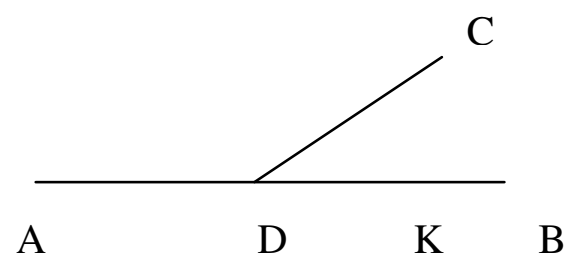

Figure 1

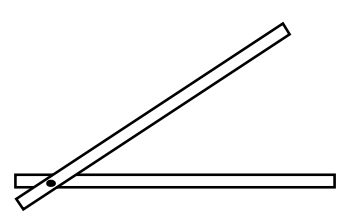

Figure 2

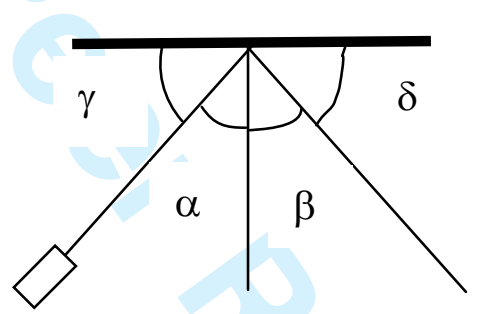

Figure 3

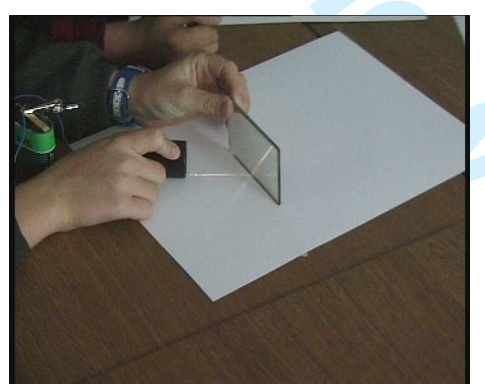

Photo 1

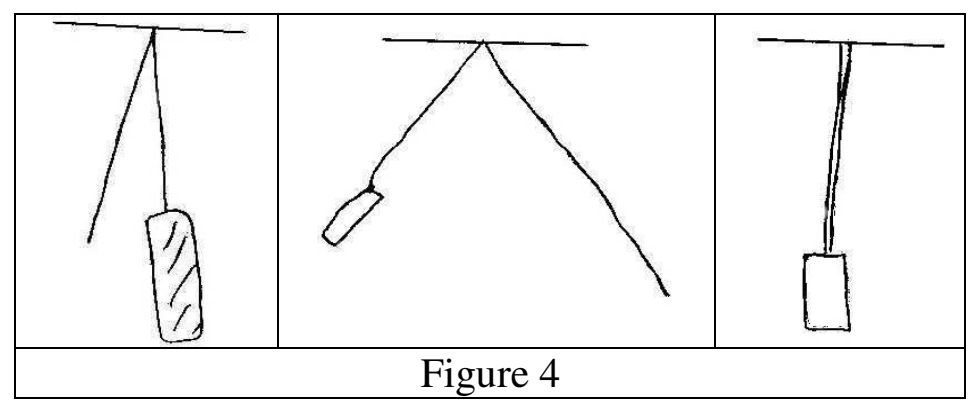




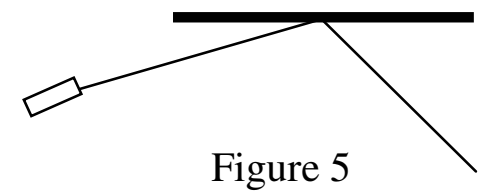

Figure 5

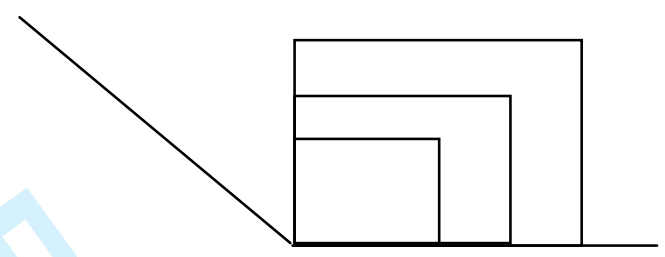

Figure 6

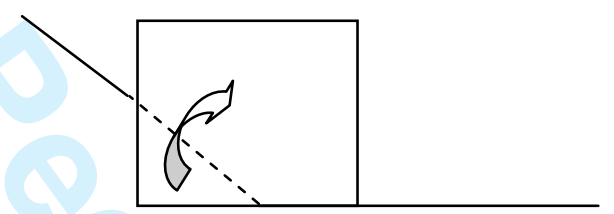

Figure 7
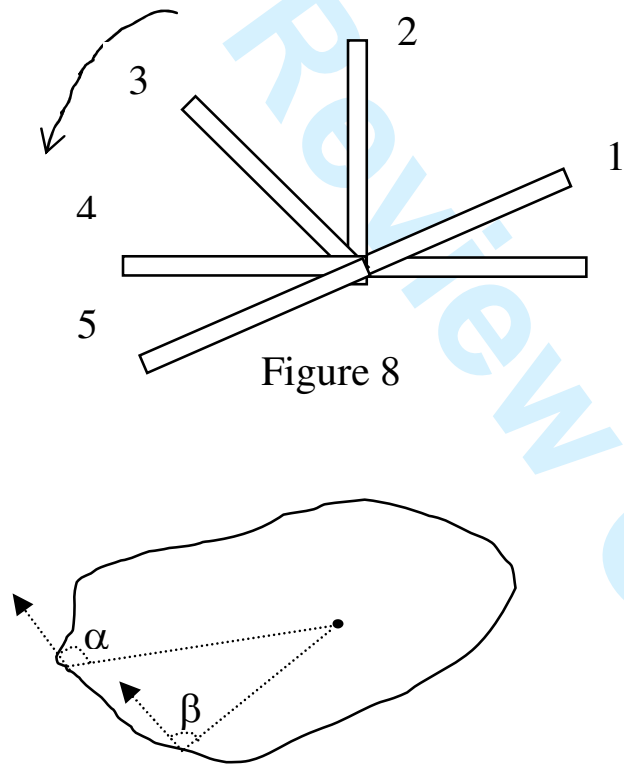

Figure 9

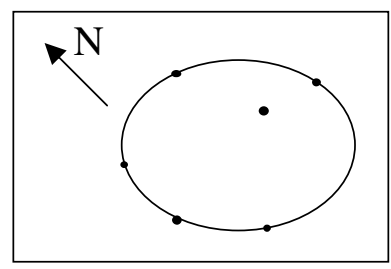

Figure 10 
(D)

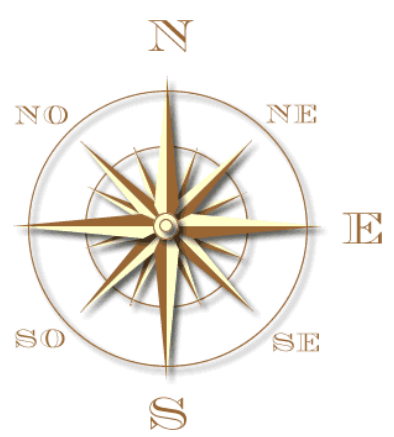

Figure 11

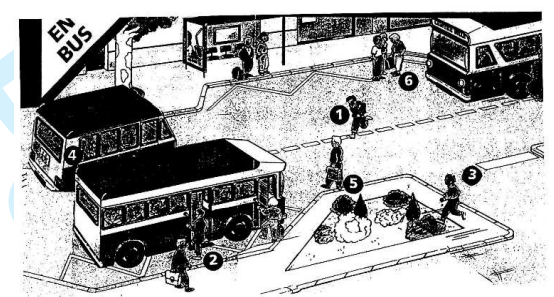

Figure 12

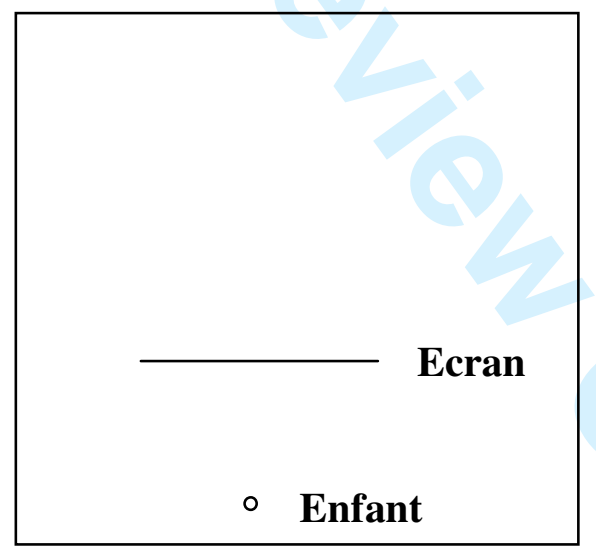

Figure 13

Table 2: student's hypothesis

\begin{tabular}{|c|c|c|c|c|c|c|}
\hline \multicolumn{2}{|c|}{ réponse correcte } & \multicolumn{2}{|c|}{ "bande" } & \multicolumn{2}{c|}{ "non obs." } & autre \\
\hline n & & & & & & \\
\hline \\
\hline
\end{tabular}



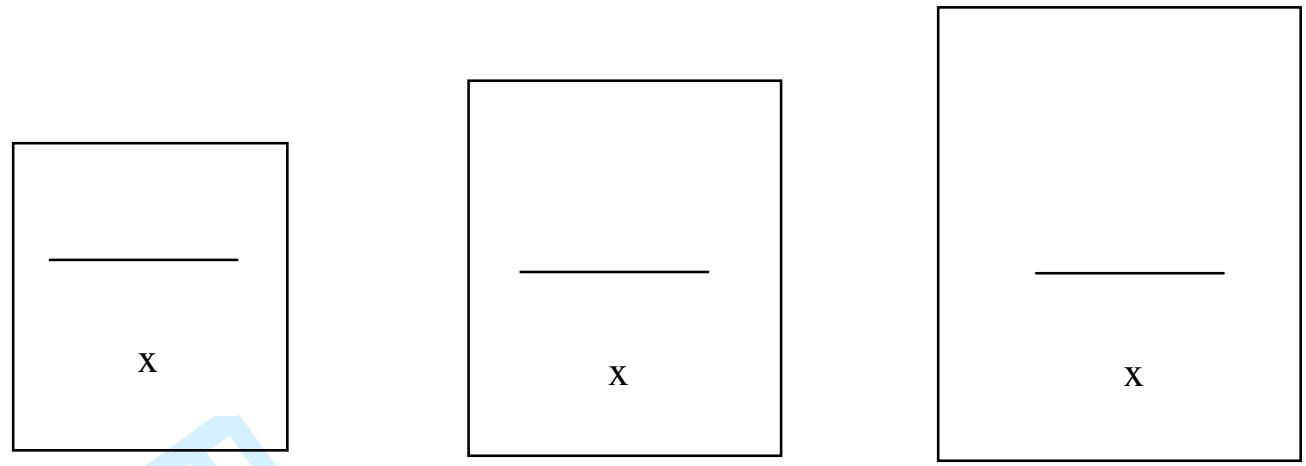

Figure 14
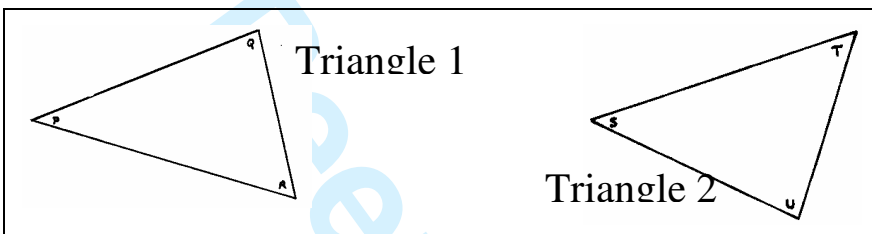

Y a-t-il dans le triangle 2 un angle égal à l'angle $\mathrm{Q}$ du triangle 1 ? Si oui lequel ?

Y a-t-il dans le triangle 1 un angle égal à l'angle T du triangle 2 ? Si oui lequel ?

Figure 15

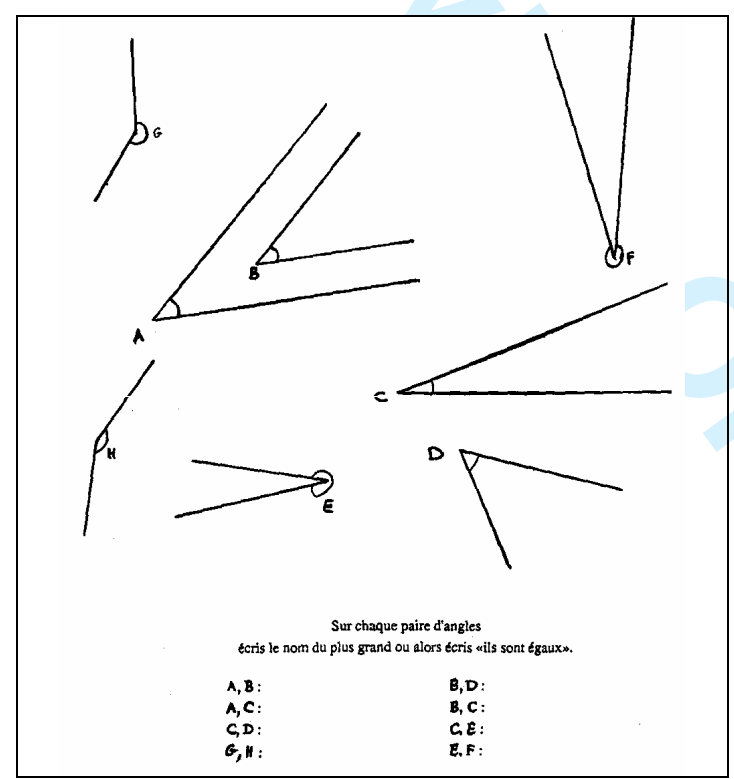

Figure 16 


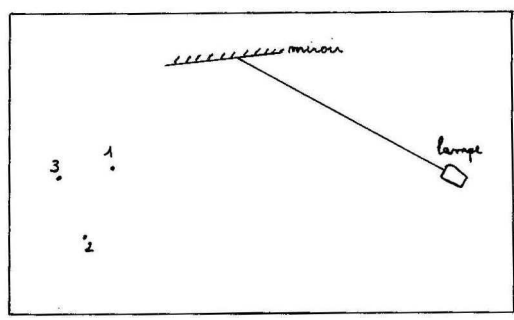

Figure 17

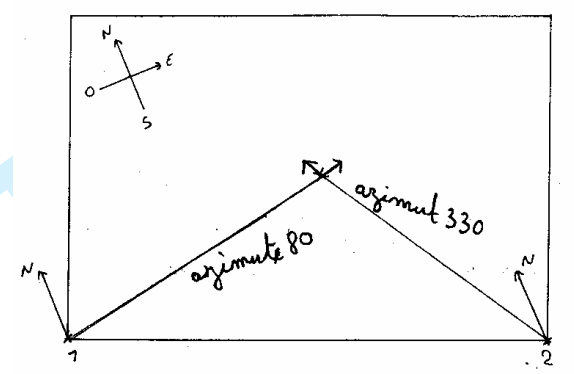

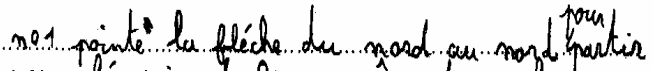

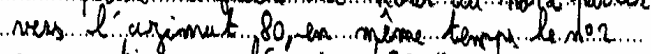

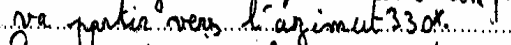

Guand m1 chotse a 2 csesai et nous troune rait . le thesor!

Figure 18
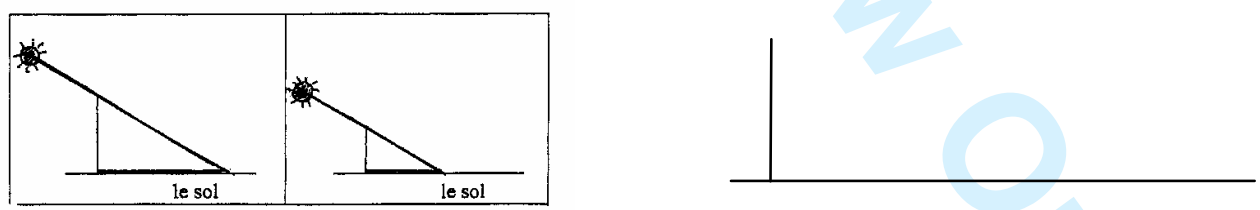

Figure 19 